\title{
CORRESPONDENCE
}

\section{DIAGNOSTIC CONTACT LENS}

To the Editorial Committee of the British Journal of OpHTHALMOLOGY

DEAR SIRS-I should be grateful if you would publish the following addendum to my paper (Sarwar, 1954).

\section{GoNIOSCOPY}

Two methods can be employed to carry out this examination after insertion of the lens in an anaesthetized eye:

(1) Examination by Reflected Light.-A very narrow slit-lamp beam is projected on to the area of angle to be examined, with the eye looking slightly away from the direction of the beam. The beam is focused on the angle and the various structures in it, and the examination is carried out along the direction of the beam.

(2) Examination by Transmitted Light.-The slit-lamp beam is projected approximately on to the angle from the same side as the area of angle under examination. Two reflexes will be seen, one on the cornea and one on the iris. The beam is then moved outwards, and when the light is on the angle the two reflexes come close together, being separated only by the narrow space of the angle itself. The angle can thus be examined by transmitted light. This method is very useful for examining the trabecula and cells in the angle.

$$
\text { Yours faithfully, }
$$

\section{SARWAR:}

\section{REFERENCE}

SARWAR, M. (1954). British Journal of Ophthalmology, 38, 626.

\section{BOOK REVIEWS}

Current Concepts of Diabetes Mellitus with Special Reference to Ocular Changes. By L. Benjamin Sheppard. 1955. Pp. 90, 16 figs, 1 col. pl., 199 refs. Blackwell Scientific Publications, Oxford. (27s. 6d.).

The early chapters in this book consist of a brief discussion of the incidence, aetiology, and physiological changes in diabetes; these are followed by a more lengthy account of diabetic ocular manifestations and a review of current concepts of pathogenesis. Prognosis under modern therapy, treatment, and complications are summarized and future research projects are suggested.

It is difficult, however, to appreciate the exact purpose of a book of this kind. The author tells us that it is presented primarily to aid the ophthalmologist in evaluating fundus changes and secondarily to inform both the patient and the internist of the diverse opinions of many investigators. To address a medical and lay audience at the same time without either irritating the former or bewildering the latter is no easy task-as this book shows. Thus the doctor is told somewhat naively that "diabetes may also be a metabolic disturbance" and that "many diabetic patients do not have visual disturbance", whereas 